\title{
Dispositivo de Segurança e Racionalidade Necrobiopolítica: Narrativas de Jovens Negros de Fortaleza
}

\author{
Aldemar Ferreira da Costa ${ }^{1}$ \\ ${ }^{1}$ Universidade Federal do Ceará, CE, Brasil. \\ João Paulo Pereira Barros ${ }^{1}$ \\ ${ }^{1}$ Universidade Federal do Ceará, CE, Brasil.
}

\author{
Dagualberto Barboza da Silva ${ }^{1}$ \\ ${ }^{1}$ Universidade Federal do Ceará, CE, Brasil. \\ Luís Fernando de Souza Benicio \\ ${ }^{1}$ Universidade Federal do Ceará, CE, Brasil.
}

\author{
Marcus Giovani Ribeiro Moreira ${ }^{1}$ \\ ${ }^{1}$ Universidade Federal do Ceará, CE, Brasil.
}

\begin{abstract}
Resumo: $\mathrm{O}$ artigo problematiza racionalidades ligadas à implantação de um dos principais dispositivos de segurança em funcionamento em periferias da cidade de Fortaleza, as Células de Proteção Comunitária (CPC), a partir de discursos de jovens negros e realizando interfaces da psicologia com a questão das relações raciais numa perspectiva de desnaturalização de preconceitos e discriminações. Trata-se de uma pesquisa qualitativa, sob a perspectiva da pesquisa-inter(in)venção, operacionalizada por entrevistas semiestruturadas e grupo de discussão com jovens da região onde a primeira CPC foi instalada. Teoricamente, traçam-se diálogos da psicologia com estudos foucaultianos sobre dispositivos de segurança, reflexões de Mbembe sobre necropolítica e discussões sobre a questão racial no Brasil. Os participantes apontam que a CPC promoveu o agravamento de racismos institucionais, expondo os jovens negros a situações de criminalização e violação de direitos. A CPC é percebida pelos jovens como emblema do desinvestimento do Estado em políticas sociais e recrudescimento de um Estado securitário, potencializando processos de precarização e segregação de vidas racializadas em prisões ou nas margens urbanas. Aponta-se que a articulação do dispositivo de segurança ao dispositivo racial se sustenta por uma racionalidade necrobiopolitica, que produz as regiões periferizadas como zonas de morte e espaços heterotópicos e reforçam a estigmatização de juventudes negras como inimigos ficcionais. Conclui-se que a pesquisa em psicologia pode se constituir um potente dispositivo de problematização de relações raciais, enfrentamento ao racismo e construção de uma psicologia Antirracista, capaz de fomentar diálogos e composições conjuntas com segmentos historicamente silenciados e subalternizados.
\end{abstract}

Palavras-chaves: Segurança, Juventude, Racismo, Pesquisa-Intervenção.

\section{Security Devices and Necrobiopolitics Rationality: Narratives of the Black Youth in Fortaleza}

\begin{abstract}
By intertwining Psychology interfaces with questions regarding race relations and based on a perspective of denaturalization of prejudice and discrimination, this article questions rationalities related to the implementation of one of the main functioning security devices in the suburbs of the municipality of Fortaleza, namely the Community Protection Cells (CPC), from a black youth point of view. It is the product of a qualitative research that adopts the research intervention perspective as well as semi-structured interviews and group discussions with young individuals who reside around the first installed CPC. Foucaultian studies regarding security devices, Mbembe's reflections about necropolitics and discussions about race issues
\end{abstract}


in Brazil are interfaced. The participants point out that CPC has promoved the aggravation of institutional racism, exposing young black individuals to situations of criminalization and violation of rights. The CPC is seen by said youth as an emblem of lack of government investment in social programs and the fortification of a police state, resulting in the precariousness and incarceration of racialized lives, whether in prisons or in urban margins like death zones and heterotopy spaces, reinforcing the stigmatization of black youth as fictional enemies. Research in Psychology is thus shown to be a powerful tool to handle race relations, confronting racism and the creation of an anti-racist psychology capable of fostering discussion and joint compositions with segments of the population who have been historically silenced and excluded.

Keywords: Security, Youth, Racism, Intervention Research.

\title{
Dispositivo de Seguridad y Racionalidad Necrobiopolítica: Narrativas de Jóvenes Negros de Fortaleza
}

\begin{abstract}
Resumen: El artículo analiza las racionalidades relacionadas con la implantación de uno de los principales dispositivos de seguridad en funcionamiento en las periferias de Fortaleza, las Células de Protección de la Comunidad (CPC), con base en el discurso de jóvenes negros y las interfaces de la psicología con el tema de las relaciones raciales en una perspectiva de desnaturalización del prejuicio y la discriminación. Se trata de una investigación cualitativa, desde la perspectiva de la investigación-intervención, posibilitada por entrevistas semiestructuradas y un grupo de discusión con jóvenes de la región donde se instaló la primera CPC. Teóricamente, se establecen diálogos de la psicología con los estudios foucaultianos acerca de dispositivos de seguridad, las reflexiones de Mbembe sobre la necropolítica y las discusiones sobre el tema racial en Brasil. Los participantes señalan que la CPC promovió el agravamiento del racismo institucional, exponiendo a los jóvenes negros a situaciones de criminalización y violación de derechos. Estos jóvenes perciben la CPC como un emblema de la desinversión del Estado en políticas sociales y el resurgimiento de un estado de seguridad, lo que resulta en la precariedad y el encierro de vidas racializadas en cárceles o en las márgenes urbanas. Se señala que la articulación del dispositivo de seguridad con el dispositivo racial es sostenida por una racionalidad necrobiopolítica que produce márgenes en las periferias como zonas de muerte y espacios heterotópicos, que refuerzan la estigmatización de los jóvenes negros como enemigos ficticios. Se concluye que la investigación en psicología puede ser un poderoso dispositivo para problematizar las relaciones raciales, confrontar el racismo y construir una psicología antirracista, capaz de mejorar los diálogos y composiciones conjuntas con segmentos históricamente silenciados y subordinados.
\end{abstract}

Palabras clave: Seguridad, Juventud, Racismo, Investigación-Intervención.

\section{Introdução}

Os crimes violentos letais e intencionais ${ }^{1}$ têm se acentuado nas regiões Nordeste e Norte do Brasil nos últimos anos (Barros, Benício, Silva, Leonardo, \& Torres, 2017). Coloca-se, então, à psicologia um desafio proeminente de enfocar os aspectos psicossociais da violência, destacando os atravessamentos de questões raciais, de classe, gênero, território e geração nessa problemática (Barros et al., 2017; Uziel, Seisleski, Barros, \& Bicalho, 2018).

Segundo o Anuário do Fórum Brasileiro de Segurança Pública (2019), somente em 2018, 63.895 pessoas foram assassinadas no país. Ainda no mesmo ano, 5.159 pessoas perderam suas vidas em

${ }^{1}$ Crimes Violentos Letais Intencionais (CVLI) é a designação criada pela Secretaria Nacional de Segurança Pública (SENAS), para a categoria de crimes de homicídio doloso, lesão corporal seguida de morte e roubo seguido de morte, esse último também conhecido como latrocínio. 
decorrência de intervenções policiais, o que representa um aumento de $21 \%$ em relação ao ano anterior. Outro dado é o número de morte de policiais: 367 somente em 2018, o que indica que tanto policiais quanto adolescentes estão cada vez mais expostos a mortes em um contexto de aprofundamento de disputas entre grupos ligados aos mercados ilegais de drogas e armas, bem como de políticas públicas de segurança calcadas no paradigma da guerra (Duarte, 2013; Karam, 2015; Zaccone, 2015).

Cabe ressaltar que o crescimento da violência urbana ora apontado, por não atingir homogeneamente a população, é mais um dos indicativos de uma persistente desigualdade racial e da perpetuação da colonialidade no Brasil (Benício et al., 2018). O Atlas da Violência de 2018, por exemplo, indica forte concentração de homicídios na população negra: entre 2007 e 2017, a taxa de homicídios de negros cresceu 33,1\%, ao passo que a de não negros teve uma redução de 3,3\% (Instituto de Pesquisa Econômica Aplicada [Ipea] \& Fórum Brasileiro de Segurança Aplicada [FBSP], 2019).

As referências técnicas para a prática da(o) psicóloga(o) no campo das relações raciais (Conselho Federal de Psicologia, 2017) apontam que a construção racial é perpassada pela participação de diversos segmentos da sociedade, inclusive pela ação do Estado. Sobre essa atuação estatal, que indica ausência na promoção de tratamento igualitário aos diferentes grupos sociais, denomina-se racismo institucional (Ipea \& FBSP, 2017).

Nesse sentido, ao pensar em estratégias de enfrentamento ao racismo institucional, materializado, por exemplo, nas violências contra jovens negros e na violação de seus direitos, torna-se necessário problematizar políticas públicas de segurança, sendo a pesquisa em psicologia uma potente aliada para isso (Benício et al., 2018). Estudos como os de Oliveira e Nascimento (2018), p. 218) justificam assim a importância para a psicologia do debate sobre relações étnico-raciais, racismo e seus atravessamentos no campo das políticas públicas:

A questão do negro, a desigualdade racial e social, historicamente presente nas sociedades do mundo em diferentes localidades, coloca a temática da exclusão, dos direitos civis e da liberdade como tema central nos estudos sobre o colonialismo, e suas diferentes formas de inscrição nas sociedades humanas. . . . O sofrimento inerente a todas as formas de desigualdades produz emocionalidades específicas, modos de subjetivação que influenciam processos de construção de identidades sociais e coletivas. Tais configurações subjetivas e individuais decorrem em políticas ideológicas, princípios políticos normativos, formas de organização social que representam os modos subjetivados de compreender e interpretar o mundo, as organizações e si mesmo.

No contexto em que Fortaleza figura como a capital brasileira com maiores índices de homicídios na adolescência (Borges \& Cano, 2017) e em que o medo tem comparecido como afeto cada vez mais central na sociabilidade cotidiana nesse e em outros contextos urbanos (Batista, 2003; Bicalho, Rossotti, \& Reishoffer, 2016), uma das principais promessas de campanha para a prefeitura de Fortaleza no pleito de 2016 foi a elevação de investimento em ações de segurança pública a serem desenvolvidas pelo Executivo municipal. Um dos grandes resultados das eleições foi a instalação de Células de Proteção Comunitária (CPC) em periferias estigmatizadas como violentas, contando, até o momento, com seis unidades (Prefeitura de Fortaleza, 2019). As CPC são o "carro-chefe" do Plano Municipal de Proteção Urbana (PMPU) da cidade de Fortaleza, anunciado pela prefeitura. A promessa de campanha passou a ser executada em fevereiro de 2018, com a instalação da primeira CPC, na calçada de um equipamento de cultura, arte, esporte e profissionalização voltado a jovens também da Prefeitura de Fortaleza, localizado na região do Grande Jangurussu, uma das territorialidades periféricas mais estigmatizadas da cidade. A implementação das CPC conta com a instalação de torres blindadas em formato arredondado com visão para todos os lados em que está circunscrita. As torres contam ainda com aparato tecnológico e com servidores que coordenam o monitoramento eletrônico das ruas que fazem parte do perímetro das células. A equipe possui também armamento de alta letalidade (Prefeitura de Fortaleza, 2017).

Em relação com esse cenário e realizando interfaces da psicologia com a questão das relações raciais, numa perspectiva de desnaturalização de preconceitos e discriminações, este artigo tem a proposta de problematizar as racionalidades que sustentam a implantação das CPC em periferias da cidade de Fortaleza, a partir da escuta e da análise das narrativas de jovens negros sobre suas experiências 
cotidianas em tais contextos. Tal proposta deriva de uma pesquisa "guarda-chuva" sobre violência, juventude e modos de subjetivação na cidade de Fortaleza, financiada pela Chamada Universal 01/2016 do Conselho Nacional de Desenvolvimento Científico e Tecnológico (CNPq) e desenvolvida pelo VIESES: Grupo de Pesquisas e Intervenções sobre Violência, Exclusão Social e Subjetivação, ligado Departamento de Psicologia e ao Programa de Pós-Graduação em Psicologia da Universidade Federal do Ceará (UFC).

$\mathrm{O}$ interesse por estudar "racionalidades" da CPC teve uma dupla inspiração. Em primeiro lugar, foi motivada pelas críticas políticas, culturais e estéticas de Mbembe (2014) sobre a racionalidade que engendra o que esse autor chama de "sujeito racial". Em segundo lugar, pelo tema específico que remete ao debate sobre formas de punição, orientou-se pelos direcionamentos metodológicos de Foucault (2012) ao explicar suas problematizações sobre a prisão. Seu foco foi pôr em análise as racionalidades que, desde o fim do século XVIII, sustentam a concepção de que a prisão seria um dos métodos mais eficazes por meio dos quais se poderia punir os infratores e delinquentes em uma sociedade. Nesse exercício, ao pensar as relações que se estabelecem entre racismo institucional e os modos de viver de juventudes periferizadas nos dias atuais, indagamo-nos: que racionalidades sustentam a proposta de implementação de torres de segurança nas margens urbanas como forma de promover "proteção comunitária"? "Proteção" de quem, contra o quê e contra quem?

Para responder a essas questões, a pesquisa recorreu a estudos foucaultianos sobre dispositivos de segurança e biopolítica, discussões de Mbembe sobre necropolítica, políticas de inimizade e crítica da razão negra. Também nos referenciamos em estudos sobre a questão racial no Brasil e sobre os agenciamentos entre juventude e violência, oriundos do campo da psicologia e de áreas afins.

Para analisarmos uma instituição, lembra-nos Foucault (2012), é necessário distinguir, em primeiro lugar, o que se chama de racionalidade, ou seu fim, isto é, os objetivos a que se propõe e os meios pelos quais se utiliza para os atingir. Em segundo lugar, é preciso discernir os efeitos produzidos a partir dos objetivos e meios implementados, os quais muito raramente coincidem com os fins propostos no programa institucional. Aponta-se, assim, para o entendimento de que, mesmo não estando esses efeitos previstos pelos fins declarados, ainda há utilidade para a manutenção de uma racionalidade que sustenta o dispositivo. A título de ilustração, sob esse ponto de vista, a prisão, que não possuía o efeito de recuperar, serviu muito mais como um dispositivo de engendramento da própria figura do delinquente. Assim, ao pensar nas racionalidades que produzem/sustentam a prisão, Foucault (2012) apresenta-nos a tese de que ela serve como dispositivo de controle social e de gestão dos ilegalismos. Em que medida essa racionalidade também permeia outros dispositivos além da prisão na atualidade, particularmente em uma sociedade colonial como a nossa, fortemente orientada por volúpias punitivas, hierarquias raciais $\mathrm{e}$ marcos de reconhecimento profundamente desiguais?

Nossa premissa teórico-metodológica é de que a CPC se configura como um "dispositivo de segurança", seguindo a discussão de Foucault (2008). Como ressaltam Lemos, Bicalho, Alvarez e Brício (2015, p. 335), o dispositivo de segurança "constitui-se como uma rede de relações constituída por elementos heterogêneos cuja formação atende à função de responder a uma urgência: a passagem da norma ao risco". Assim, os dispositivos de segurança passam a exercer a governamentalidade não apenas das delinquências, mas também de vidas que são reguladas por tais dispositivos (Lemos et al., 2015).

Sueli Carneiro (2005), ao se apropriar da noção de dispositivo elaborada por Foucault, constrói a noção de dispositivo de racialidade, buscando discutir como os processos de exclusão de populações negras, assim como suas consequências, dão-se a partir de tecnologias de poder, e oferece-nos um debate sobre como tais tecnologias têm subalternizado populações negras no Brasil. Essa compreensão aqui nos é importante, pois nossa hipótese é que dispositivo de segurança e dispositivo racial se articulam em territorialidades periféricas estigmatizadas pela violência, especialmente no tocante à gestão da vida e da morte de determinados segmentos juvenis.

Como lembra Almeida (2018), em sua discussão sobre racismo estrutural, a sociedade cria marcadores próprios de diferenciação e hierarquização, observando que esses marcadores servem como mecanismos de distinção social a partir da decodificação dessas diferenças e seu câmbio em estigmas e estereótipos. É a partir dessa diferença, plasmada nos modos de subjetivação, que o poder é exercido e distribuído. A diferença funciona como esteio de hierarquização social, do (não)reconhecimento de direitos e de legitimação do arbítrio e de um amplo espectro de violências. 
O racismo aqui é compreendido como legitimação para um exercício de poder, que se materializa nas relações sociais, interpessoais, políticas, jurídicas e econômicas (Almeida, 2018; Schwarcz, 2019). Um tipo de poder efetivo e real, que resulta de uma fantasmagoria ou, nas palavras de Mbembe (2017, p. 27), "de uma ficção útil, de uma construção fantasista ou de uma projeção ideológica". Ainda que raça seja uma fantasmagoria, que não seja um fato natural, biológico ou físico, uma série de subsídios raciais têm servido como esteio para o governo e modulação de condutas e para a produção de etiquetas das relações sociais baseadas no mando e na obediência. Tais processos, contudo, são naturalizados pelo mito da democracia racial, por meio do qual se tenta negar a existência de racismo no Brasil (Nascimento, 2017).

\section{Percurso metodológico}

\section{Caracterização da pesquisa}

A proposta metodológica da pesquisa se delineou com abordagem qualitativa, especificamente a partir da perspectiva da pesquisa-inter(in)venção orientada pelo método da cartografia (Benício et. al., 2018). A pesquisa-intervenção, para Aguiar e Rocha (2007), constitui-se como um tipo de pesquisa participativa que visa investigar a pluralidade qualitativa da vida de sujeitos e grupos com vistas a também promover transformações micropolíticas nesses cotidianos. Desse modo, interrogando os múltiplos sentidos produzidos e cristalizados nas instituições presentes na realidade social estudada, é que a pesquisa intervenção se coloca também como exercício desnaturalizador de práticas institucionais e de seus efeitos no cotidiano. A cartografia, para Barros e Kastrup (2009), é um ethos de pesquisa que acompanha processos de produção de subjetividades, mapeando o plano coletivo das forças nos quais tais processos são engendrados, atentando para suas nuances e movimentações.

\section{Local do estudo}

A pesquisa teve como locus o Grande Jangurussu, situado na periferia de Fortaleza. É uma região formada por um conjunto de comunidades. Seu surgimento data da década de 1970, quando migrantes do interior do Ceará, fugindo da seca, passaram a instalar-se com suas famílias às margens do aterro sanitário ali construído. O lixão do Jangurussu, como ficou conhecido, foi também por muito tempo a fonte de renda de muitas dessas famílias.

Foi na região do Grande Jangurussu, nas proximidades de um dos equipamentos do Centro Urbano de Cultura, Arte, Ciência e Esporte (CUCA), ligado às políticas de juventude da Prefeitura de Fortaleza, onde foi instalada, em fevereiro de 2018, a primeira Célula de Proteção Comunitária. Segundo dados mais recentes da Prefeitura de Fortaleza (2014), o Índice de Desenvolvimento Humano (IDH) do bairro figura nas piores posições entre os bairros da capital com uma taxa de 0,172, o que representa baixo nível de desenvolvimento. Ainda conforme o Comitê Cearense Pela Prevenção De Homicídios na Adolescência (2018), foram mortos 981 adolescentes somente no ano de 2017. No Jangurussu, 31 assassinatos de jovens foram registrados naquele ano, sendo, junto com o Bom Jardim, o bairro com maior número de mortes desse segmento populacional na cidade de Fortaleza.

\section{Participantes do estudo}

Os participantes do estudo foram jovens autodeclarados(as) pardos(as), pretos(as) ou negros(as) seguindo as normas técnicas do Instituto Brasileiro de Geografia e Estatística (IBGE), que agrupa, para a formação da classificação de negros(as), a população autodeclarada preta ou parda (Petruceli \& Sabóia, 2013) - que moram no Grande Jangurussu e que frequentam espaços próximos à instalação da CPC. Ao total participaram dezesseis jovens, de ambos os sexos, os quais, além de morarem naquela região, faziam parte de coletivos ou instituições que tematizam a arte e movimentos culturais na reivindicação de reconhecimento e afirmação do povo preto, pobre e periférico, tensionando as políticas públicas na gestão de melhorias na qualidade de vida do território em que vivem.

\section{Estratégias e instrumentos metodológicos}

O procedimento de investigação desta pesquisa se deu por meio de: a) quatro entrevistas semiestruturadas com o manejo da cartografia (Tedesco, Sade, \& Caliman, 2013), sobre como percebem as implicações da instalação da CPC nos seus cotidianos. Nas entrevistas, participaram quatro jovens autodeclarados(as) negros(as) moradores(as) do Jangurussu com faixa etária entre 23 a 29 anos, sendo três homens e uma mulher. São jovens oriundos(as) de famílias de baixo poder aquisitivo, de escolaridade média e com 
vivências de violência e exclusão social. Os nomes dos(as) participantes aparecerão aqui, ficticiamente, como: José, Luís, Zumbi e Dandara. Nas entrevistas, foram tratados assuntos relacionados ao cotidiano e aos modos de habitar o território e às percepções sobre violência no bairro. Foram abordados diretamente os sentidos que aqueles(as) jovens negros(as) produziam sobre a implantação da CPC e suas consequências em seus cotidianos. Nesta pesquisa, seguiu-se a técnica da "bola de neve", em que cada participante indicou outro(a) que pudesse colaborar com o estudo. O número de participantes foi definido pelo critério de "saturação". Os registros se deram via gravações de áudio; e b) grupo de discussão sobre segurança no cotidiano de jovens moradores(as) do Jangurussu. A realização desse grupo foi facilitada pelo fato de que já havia uma ação de extensão realizada pela equipe de pesquisa junto a um coletivo de jovens naquela região. $\mathrm{O}$ grupo de discussão contou com doze participantes daquele coletivo, de ambos os sexos, autodeclarados(as) pretos(as) ou pardos(as). São jovens moradores(as) de uma das comunidades da região do Jangurussu, localizada logo atrás da CPC instalada naquela região.

Em 2018, aproximamo-nos desse grupo para acompanhar suas atividades e propusemos oficinas sobre juventudes e direitos humanos, cujas temáticas específicas foram elencadas pelos(as) próprios(as) participantes. Ao longo desse acompanhamento, conversamos com eles(as) sobre suas trajetórias de vida a partir de discussões sobre direitos das juventudes, com o intuito de potencializar aquele grupo, já que demonstravam interesse em formar um coletivo juvenil para tratar de questões relacionadas às precarizações e às formas de resistência que experimentam naquela territorialidade, especialmente no que diz respeito ao racismo.

Caracterizamos o grupo com o qual mantivemos diálogos para a tessitura da pesquisa para que as práticas de resistências elaboradas pelos(as) participantes frente ao racismo institucional ganhe visibilidade na composição deste texto. Assim sendo, uma das formas em que se pôde perceber a incidência micropolítica dos(as) adolescentes e jovens frente ao modelo de segurança pública adotado pelo Estado e aos mecanismos do racismo advindos desse modelo foi a própria construção grupal para debater essas questões e, mais especificamente, a sugestão, feita por eles(as), de que seria necessário discutir como a polícia tem atuado em sua comunidade. Antes dessa sugestão, já haviam pontuado diversas vezes nas discussões sobre direitos das juventudes como as abordagens policiais reverberam em suas vidas. Toma-se aqui a fala e a denúncia como uma incidência micropolítica desses(as) adolescentes e jovens na medida em que posicionar-se contra algo que opera no silenciamento de certas existências possa quebrar essa máscara de silêncio do qual nos aponta Kilomba (2017). A máscara, marca da colonialidade (Kilomba, 2017), pode ser entendida aqui como uma operação do epistemicídio (Carneiro, 2005) contra populações negras. $\mathrm{O}$ ato da fala é uma prática que afirma a sua realidade e as existências desses(as) adolescentes e jovens, já que a lógica do epistemicídio atuaria desacreditando e efetivamente calando as opressões gestadas no racismo em corpos racializados.

No que diz respeito à proposta metodológica do grupo de discussão, solicitamos aos(às) participantes que construíssem um esquete (uma cena) de como as ações de segurança ligadas à CPC têm acontecido na comunidade, com base nas experiências dos(as) participantes ou em situações do cotidiano de sua comunidade que lhes tenham sido narradas por parentes, amigos(as) ou conhecidos(as) também jovens e negros(as). Realizado o esquete, seguiu-se a discussão sobre o tema que, além dos conteúdos trazidos na cena, contou com a leitura coletiva de matérias jornalísticas que noticiavam sobre segurança pública no Jangurussu: a primeira celebrava a inauguração da torre de vigilância na periferia; a segunda mostrava o prefeito da cidade reunido com empresários do setor lojista falando da importância das células de proteção e do aumento do aparato policial como estratégia para garantir a segurança das pessoas ao irem consumir no mercado local; e a terceira falava do aumento assustador do número de homicídios de jovens, destacando que Jangurussu estava entre os bairros em que havia aumentado o número de mortes juvenis. Os registros do grupo de discussão se deram via diário de campo.

\section{Análise dos dados}

Para a análise de dados, utilizou-se a análise de discurso de inspiração foucaultiana articulada à proposta da análise cartográfica (Barros \& Barros, 2014), o que significou destacar as diversas vozes e o plano coletivo das forças ligadas ao processo investigado a partir da construção de analisadores que indicaram a rede de saber-poder-subjetivação na qual tal 
processo é produzido. Para Aguiar e Rocha (2007, p. 656), "analisadores podem ser acontecimentos, práticas ou dispositivos que sinalizam, mediante seu próprio modo de funcionar, aspectos impensados de uma estrutura social”. Ademais, conforme Foucault (1986, p. 144) "não há enunciado que não suponha outros; não há nenhum que não tenha, em torno de si, um campo de coexistências".

\section{Resultados e discussões}

Um dos pontos de convergência dos discursos dos(as) participantes foram de sentidos que ressaltavam a racionalidade de controle que orientaria a instalação da CPC. Um dos entrevistados aponta que tal dispositivo serviria para "controlar, vigiar, avaliar, quer condicionar a gente, nosso comportamento" (Zumbi, 2018). Os(as) participantes apontam que o aparato tecnológico de vigilância instalado com a Célula objetivaria controlar o trânsito de determinadas vidas tidas como "perigosas", a fim de promover certa sensação de segurança para a comunidade a partir de ações preventivas e ostensivas. No entanto, cabe-nos interrogar: quais sujeitos estão sendo protegidos(as)? E de quais existências estes sujeitos precisariam se proteger?

Para Reiner (2004, p. 20), controle social pode ser entendido como "tudo aquilo que contribui para a reprodução da ordem social". Nesse sentido, o autor ressalta que a polícia exerce de modo efetivo o controle sobre as pessoas que se comportam de modo a desagradar, incomodar ou que são indesejáveis. Conforme aponta Bicalho (2014), o que justifica certos dispositivos de segurança é o uso do medo como operador político e o enquadramento de jovens negros como naturalmente violentos e potencialmente perigosos (Coimbra \& Nascimento, 2005), o que remete a perspectivas higienistas e de defesa social que se voltam à gestão da vida e dos trânsitos desses corpos, definindo quem pode e quem não pode circular pela cidade. Com efeito, tais dispositivos atuariam na reprodução de condições para a constituição das periferias urbanas como espaços heterotópicos (Foucault, 2013), caracterizados pela exceção, pela exclusão e pela extraterritorialização, isto é, espaços à margem da lei, de direitos básicos e de condições de reconhecimento social (Birman, Leite, Machado, \& Carneiro, 2015).

Ainda sobre isso, Foucault (2014) discorre sobre como essas formas "preventivas", que se configuram como estratégias para designar e punir previamente possíveis delinquentes, definem-se a partir de quem é "punível", permitindo o controle das virtualidades concernentes ao que e a quem é construído como "ameaçador".

Inspirando-nos na problematização que Foucault (2012) realiza sobre a prisão, se, por um lado, os(as) jovens questionam a eficácia da implantação de torres de segurança com aparatos tecnológicos e polícia armada na diminuição de índices de violência nas periferias, por outro, suas narrativas permitem a análise segundo a qual tal dispositivo é efetivo especificamente na produção da própria figura do infrator/criminoso, antes mesmo de algum cometimento de ato infracional ou crime, justificando métodos punitivos e atualizando a produção de sujeitos potencialmente perigosos encarnados em corpos jovens e negros, aspecto destacado pela discussão de Coimbra (2001). Segundo relato dos(as) participantes sobre suas experiências cotidianas:

As coisas continuam acontecendo tão quanto aconteciam antes da torre, então a sensação de segurança que as pessoas achavam que teriam não tá tendo, não mudou nada. Agora tendo o contato que eu tenho com as pessoas que moram no entorno a gente sente um impacto muito grande, muita violação de direitos, muita invasão de casas, muita agressão de polícia, os policiais e os guardas não são identificados, não há respeito nenhum nem com a comunidade no geral nem com a identidade das pessoas, a privacidade das pessoas, muito menos com os direitos delas, então se eu for fazer uma avaliação no geral mudou, mas mudou pra pior (Dandara, 2018).

Foram recorrentes os relatos dos(as) jovens negros(as) moradores do Jangurussu acerca do recrudescimento de uma tendência de criminalização de jovens negros a partir da instalação da CPC. Isso pode ser exemplificado pelo seguinte trecho de uma das entrevistas.

A periferia é o alvo da polícia, é o alvo do Estado porque, mesmo que eu não seja bandido, eu me visto como bandido, mas não que eu me vista como o bandido, os bandidos que se vestem daquela forma porque é a forma que a periferia se veste, são os nossos trajes, é o jeito que a gente se veste. Então, é o estereótipo que nós vestimos, infelizmente é assim. A periferia é criminalizada (Luís, 2018). 
De acordo com Juliana Borges (2018), a criminalização, impulsionada pela "guerra às drogas", é uma forma de perpetuar uma lógica colonial e um dos principais aparatos de manutenção do racismo, aprofundando vulnerabilidades calcadas em hierarquias raciais. Já para Alexander (2018), a criminalização de negros e despossuídos - que se traduz tanto no encarceramento em massa quanto no incremento de políticas de segurança pública voltadas à vigilância de populações e territorialidades periferizadas sob um verniz de enfrentamento à violência - ganha centralidade no remodelamento e readequação de um sistema de controle social racializado.

Segundo as narrativas dos(as) participantes da pesquisa, expressando-se a partir do aumento das abordagens policiais, as atuações ligadas à CPC têm recorrido a notórios subsídios raciais, pois tratariam diversos jovens negros que circulam naquela região como "elementos suspeitos" (Misse, 2008), perpetuando segregações na cidade e nas próprias periferias entre aqueles considerados "semelhantes", vistos como sujeitos de direitos, e aqueles tratados como "dessemelhantes", destituídos de estatuto político (Mbembe, 2017). A CPC, produzida para responder a um tipo de apelo por segurança, passaria, com base nas narrativas dos(as) participantes, a operar como dispositivo de controle da circulação dos corpos negros e periferizados, ao precarizá-los ainda mais pela indução de condições desiguais de se movimentar pelos espaços públicos.

A relação entre racismo e polícia, mesmo sendo muitas vezes a tônica da execução das políticas de segurança pública, constitui-se em uma dimensão recalcada da atuação policial (Moreira, 2013). Um exemplo disso é o caso das abordagens policiais, citadas pelos(as) participantes da pesquisa, e do poder discricionário garantido ao policial nos casos de busca pessoal. A lei não menciona critérios objetivos para a formulação da chamada "fundada suspeita" e essa ausência de critérios objetivos, no dia a dia das práticas policiais, abre precedentes para a filtragem racial na atribuição da suspeição, elegendo comumente indivíduos negros que, aliados a outros marcadores como classe social, geração, gênero e território, são uma das principais corporificações do crime e do perigo (Ramos \& Musumeci, 2005).

No grupo de discussão, os(as) participantes disseram que alguns jovens negros do Jangurussu que encarnam essa figura da suspeição são conhecidos como "para-raio", pois são constantemente abordados pela polícia. O "para-raio" ou "pirangueiro" são expressões nativas utilizadas para designar o jovem morador de periferia que traz no seu corpo marcadores sociais que o identificariam como um sujeito que representa um potencial perigo. A forma de se vestir, com blusas e bermudas de marcas específicas, a utilização de adereços, como boné de aba reta e cordões dourados, o uso de bigode e a presença de tatuagem, o modo como anda e se articula, o vocabulário, o lugar onde mora e, sobretudo, a cor costumam operar como aspectos definidores de quem é esse sujeito a quem tanto se teme e do qual é necessário se proteger (Moreira, 2013).

Também no grupo de discussão, pedimos que os(as) participantes evidenciassem alguns pontos da cena por eles(as) desenvolvida acerca da atuação policial no bairro em que vivem, como: por que dois adolescentes não foram revistados? Um dos participantes usou a expressão "cara de bandido"; outros responderam que "o lugar onde a pessoa mora, o modo de vestir, a cor da pele" definem quem a polícia para. Acerca da seletividade racial, um adolescente chegou a dar um exemplo segundo o qual, em uma abordagem a que fora submetido, os policiais deixaram o seu amigo branco ir embora sem ter sido revistado. Tentamos retomar a expressão "cara de bandido", que circulou no grupo, perguntando que significado isso tinha para eles(as). Desse modo, os(as) participantes elencaram o modo de andar, as vestes e a cor da pele como elementos determinantes para essa categorização.

Assim, o relato dos(as) participantes sobre suas experiências envolvendo a CPC põem em xeque o mito da democracia racial, aspecto discutido por Nascimento (2017) ao problematizar o genocídio do negro no Brasil. A partir das narrativas produzidas nas entrevistas e no grupo de discussão, podemos considerar que dispositivos de segurança como a CPC são emblemáticos para compreendermos como se dá a ocupação colonial tardia, que, segundo Mbembe (2017), articula disciplina, biopolitica e necropolitica. São emblemáticos também para a problematização de como opera o racismo em tempos neoliberais, produzindo o que Mbembe (2014) chama de "devir negro do mundo", que diz respeito à tendência de universalização da condição negra a diversos grupos subalternizados, supérfluos ao funcionamento do capital e submetidos ao abandono que converte a precarização induzida e institucionalizada em padrão de vida. 
Almeida (2018), a partir do diálogo com Foucault e com Mbembe, lembra que as funções do racismo envolvem a divisão e a fragmentação, produzindo formas de hierarquias entre as raças, bem como a autorização da morte daqueles pertencentes a raças consideradas inferiores. Para Mbembe (2017), o racismo colonial torna-se o motor da necropolitica, que tem como base o estado de exceção e a ficcionalização de inimigos.

As narrativas dos(as) participantes corroboram o ponto de vista de Andrade e Andrade (2014), segundo o qual, no Brasil, o racismo na relação entre raça, crime e justiça é observado cotidianamente, seja pelas ações institucionais e dos agentes que operam as políticas públicas, pela omissão do Estado sobre certas condições de vida e determinadas práticas institucionais promotoras de desigualdades, sobretudo sociorraciais, seja pelo ato de certos grupos e indivíduos na promoção de discriminação e estigmatização de negros(as) em diversas dimensões, inclusive na violação e negação dos direitos dessa população.

A CPC é percebida por aqueles(as) jovens como emblema do desinvestimento do Estado em políticas sociais e do recrudescimento de um Estado securitário. Ao refletir, na entrevista, sobre a situação da violência no local onde vive, um dos jovens aponta: "se você pensar o local que ela está instalada, é do lado de um equipamento público de juventude, então existe já um descaso, que é o que eles querem, né, que a juventude não tome esses espaços" (José, 2018). Outro jovem, também em entrevista, sinaliza que políticas de segurança como a instalação das torres de segurança "são só plataformas pra adquirir voto" (Zumbi, 2018). Outro participante entrevistado, ao denunciar as condições indignas de vida a que estão submetidos os jovens negros que frequentemente seriam alvos das ações da CPC, foi enfático: “o Estado não tá interessado [naqueles jovens e no enfrentamento da violência no Jangurussu]; se estivesse, ao invés de ter gastado os milhões para construir as torres, tinha investido nas escolas, tinha investido em outras várias ferramentas de juventude que tá sendo sucateada por aî" (Luís, 2018).

A polícia comunitária, segundo Gadelha e Duarte (2014), em seu desenvolvimento recente, guarda uma próxima relação com o estado neoliberal. Nesse sentido, observa-se maior presença do Estado Policial em zonas em que se concentram as maiores taxas de violência e letalidade e a diminuição da sua existência, nesse mesmo território, daquilo que se refere a um Estado social (Wacquant, 2001). Segundo Pereira, Pontes, Magalhães e Maciel (2019), entre 2006 e 2018, a Prefeitura de Fortaleza aumentou em $223,8 \%$ os gastos com segurança pública, notando-se ainda a diminuição da execução orçamentária para políticas públicas voltadas para crianças e adolescentes em Fortaleza. Os efeitos desse tipo de estreitamento orçamentário têm sido percebidos pelos(as) jovens, pois, segundo eles(as), a construção de um teatro no CUCA, também de responsabilidade da Prefeitura de Fortaleza, já dura anos e ainda não foi concluída. Problematiza-se essa ausência estatal que, na prática, apresenta-se precariamente enquanto um Estado Social ao mesmo passo que está muito presente na forma de Estado Policial, numa lógica punitivo-penal apoiada em dispositivos de segurança fortemente presentes nesse território, como podemos considerar a CPC.

Na perspectiva do(a)s participantes, a instalação da CPC tem o intuito de tentar circunscrever a violência à periferia, numa espécie de "zoneamento". Segundo um dos participantes, "só colocam a torre pra essa violência não ultrapassar fronteiras, mas a violência aqui é que nem uma bruxa solta" (Zumbi, 2018). Assim, levando em consideração que uma das principais características do capitalismo atual tem sido a da produção de uma população “supérflua” (Mbembe, 2019), uma das técnicas para tal é o enclausuramento desses grupamentos em "zonas de morte", sejam as prisões ou as próprias periferias, como "presos a céu aberto" (Pedro et al., 2012). Neste último caso, as novas tecnologias de segurança, como o videomonitoramento, produzem formas de controle em que os cidadãos comuns e os agentes estatais participam do processo de vigiar, agindo seletivamente sobre determinados corpos que têm cerceados seu direito de transitar e seu direito de habitar a cidade pelo recrudescimento de estigmatizações e segregações socioespaciais. De acordo com as experiências vividas pelos(as) jovens com quem dialogamos, a instalação da Célula, que remete a um processo de "securitização" de que nos fala Mbembe (2019), tem se exercido a partir de uma racionalidade necrobiopolítica, isto é, que indissocia regulação biopolítica e gestão necropolítica na produção de "vidas vivíveis" e "vidas matáveis", a partir de um conjunto de técnicas e atributos que qualificam e distribuem diferencialmente o reconhecimento de humanidade e o direito à vida (Bento, 2018).

Os(as) jovens ouvidos(as) na pesquisa denunciam o que consideram ser uma seletividade racial na 
execução das ações da CPC, conforme relato a seguir: "todo mundo sabe que a população negra é a que é mais vista pela polícia, né??” (José, 2018). Davis (2018) dá-nos elementos para compreendermos que a seletividade racial que tem conduzido o encarceramento em massa também norteia a ampliação dos dispositivos de segurança nas periferias. Ou seja, jovens e negros moradores de periferias tendem a ser aqueles sobre os quais mais recai a vitimização desse tipo de norma. Segundo Flauzina (2006), os dispositivos de segurança são autorizados a exercer o poder por meio de ações repressivas; contudo, esse tipo de abordagem se dá mais frequentemente em determinados territórios periferizados e sobre as existências negras.

Os territórios estigmatizados nos quais foram instaladas as CPC se aproximam da descrição feita por Mbembe (2017), quando, a partir do diálogo com Franz Fanon, discorre sobre as colônias contemporâneas como lugares que experimentam um lugar particular de terror, precariedade e má fama, também povoado por pessoas assim reconhecidas (Mbembe, 2017). O autor camaronês mostra que militarismo e capital se articulam para a produção dessas existências supérfluas e matáveis. Já para Lazzarato (2014), o Estado neoliberal justifica a intervenção permanente nessas áreas precárias de modo a atuar na gestão das desigualdades a partir de processos de sujeição social. Nessa lógica, os dispositivos de segurança têm atuado como pilares dessa governamentalidade neoliberal, como apontava Marielle Franco, mulher negra brutalmente assassinada por sua atuação política. Para ela, o objetivo dessa lógica militarizada

é manter os pilares de ampliação do lucro e do Estado Penal, ... que compõe elementos fundamentais do modelo neoliberal em curso. Isso porque a ocupação militar ou da polícia servirá para ampliar o espaço para a chegada de novos negócios, o que visa garantir a ação da propriedade privada tão somente enquanto os moradores ficarem em segundo plano, na defesa de sua vida e de suas liberdades (Franco, 2014, p. 48).

A atuação da CPC é então percebida pelos(as) jovens negros(as) participantes da pesquisa como um dispositivo de fortalecimento de racismos institucionais:

Vamos imaginar uma abstração: vamos supor que tem um muro eque nesse muro tem uma rachadura.
A rachadura só aumentou. Tá sendo derramado muito sangue e ele botam muitos baldes, ... baldes e baldes e nunca, nunca para. Porque eles não cuidam na fissura, né, só colocam baldes. E é como se esse balde fosse a torre aqui, só se gasta dinheiro, mais dinheiro, mais corpo, mais arma, mais bala, mais viatura, mais tribulação pro coração, mais batalhão. ... Só se gasta dinheiro, é como se fosse a fantástica fábrica né, de produzir violência (Zumbi, 2018).

A partir dos relatos dos(as) participantes, podemos considerar a CPC como um dispositivo de governamentalidade securitária ligado a uma racionalidade ao mesmo tempo necropolitica e biopolitica (Bento, 2018). Trata-se de uma racionalidade necropolítica, por articular exceção e produção de inimigos ficcionais a partir de processos de racialização de certas existências tornadas supérfluas, maximizando sua exposição à condição de precariedade. Ao mesmo tempo, constitui-se uma racionalidade biopolítica porque, ao controlar as formas de habitar e ocupar o território, regula também modos de viver nas periferias, haja vista a promoção de vidas vivíveis e que tem a liberdade de habitar e transitar pelos espaços da cidade, e vidas matáveis, aquelas submetidas a uma precarização induzida e desigual, sem lar e sem estatuto político, das quais esse dispositivo de segurança deve se ocupar para manutenção da ordem (Mbembe, 2017).

\section{Considerações finais}

Ao discutir racionalidades que produzem e sustentam a implantação das CPC em Fortaleza, tomando por base um conjunto de produções discursivas de jovens negros(as) da região do Jangurussu sobre as repercussões da ação de tal dispositivo de segurança em seus cotidianos, identificou-se que, de acordo com os(as) participantes, a CPC tem servido à manutenção de uma lógica de controle sobre corpos racializados, visto como supérfluos e potencialmente perigosos, e sobre territórios historicamente estigmatizados. Com efeito, apontamos que a CPC parece se orientar por uma racionalidade necrobiopolítica, a qual maximizaria as articulações entre dispositivo de segurança e dispositivo da racialidade, reforçando a produção de "vidas vivíveis", que devem ser protegidas e podem habitar a cidade, e "vidas matáveis", a serem controladas em suas movimentações e que personificam a violência, a insegurança e os inimigos a serem aniquilados, 
simbólica e, em muitos casos, fisicamente. As experiências narradas pelos(as) participantes também permitem refletir sobre como ações ostensivas vêm sendo ampliadas pela utilização de tecnologias de vigilância, em meio a conexões cada vez mais contundentes entre a axiomática do capital e militarização da vida em tempos de governamentalidade neoliberal.

As narrativas dos(as) participantes apontam que a CPC promoveu o agravamento de racismos institucionais, expondo jovens negros(as) a situações de criminalização e violação de direitos. A CPC é percebida por jovens negros(as) como emblema do desinvestimento do Estado em políticas sociais e recrudescimento de um Estado policial e penal, o que resulta na precarização de vidas periferizadas. A escuta de jovens negros(as) que pautam o enfrentamento ao racismo nos territórios em que vivem também permitiu concluir que a racionalidade necrobiopolítica que orienta a atuação de dispositivos de segurança nas regiões periféricas produz as margens urbanas como zonas de morte e espaços heterotópicos, assim como reforça a estigmatização de juventudes negras nelas inseridas, privadas em diversas ocasiões do direito de habitar a cidade e do acesso a equipamentos culturais em seus próprios bairros.

Aponta-se, desse modo, para processos de sujeição de populações das margens urbanas por meio de processos de segregação socioespacial. A CPC é percebida por aqueles(as) jovens como emblema do desinvestimento do Estado em políticas sociais e recrudescimento de um Estado securitário, resultando na precarização e no enclausuramento de vidas racializadas, seja em prisões seja nas margens urbanas, como prisioneiras a céu aberto. Os relatos apontam, ainda, que a instalação da Célula de Proteção também ampliou a exposição da juventude negra à violência institucional e que esta segue intimamente ligada ao racismo estrutural (Almeida, 2018).

$\mathrm{O}$ racismo atua sendo motor da racionalidade necrobiopolítica que sustenta certos dispositivos de segurança em operações nas periferias, como no caso da CPC. Frente a esse campo de problematização das desigualdades raciais, que se atualiza nas práticas institucionais, faz-se relevante afirmarmos o papel fundamental da psicologia no enfrentamento do racismo como permanência histórica e estrutural, sendo vivenciado cotidianamente por existências diaspóricas. Esse enfrentamento é condição para a defesa radical da democracia. Em suas práticas, no processo de formação permanente e nas intervenções cotidianas, a psicologia deve problematizar tal estrutura e, para isso, deve, dentre outros aspectos, abrigar cada vez mais ações que enfrentem as desigualdades e as sujeições imanentes ao racismo, seja por meio de atividades de extensão, pesquisa ou ensino curricular, afirmando um posicionamento anticolonial e antirracista.

Por isso, acreditamos que a pesquisa em psicologia, especialmente aquela que se desenha dentro de um paradigma ético-estético-político, como a que produzimos COM esses(as) jovens, pode ser uma importante aliada na luta antirracista, desmontando, nesse caso, políticas e dispositivos de segurança, destacando suas racionalidades e seus efeitos no cotidiano de jovens negros(as) inseridos(as) nas margens urbanas, a partir do diálogo com esses segmentos historicamente silenciados(as) por uma lógica colonial que ainda se atualiza fortemente no Brasil.

\section{Referências}

Aguiar, K. F., \& Rocha, M. L. (2007). Micropolítica e o exercício da pesquisa-intervenção: Referenciais e dispositivos em análise. Psicologia: Ciência e Profissão, 27(4), 648-663. https://doi.org/10.1590/S1414-98932007000400007

Alexander, M. (2018). A nova segregação: Racismo e encarceramento em massa. Boitempo.

Almeida, S. (2018). O que é racismo estrutural?. Letramento.

Andrade, F., \& Andrade, R. (2014). Raça, crime e justiça. In R. Lima, J. Ratton, \& R. Azevedo (Orgs.), Crime, polícia e justiça social no Brasil (pp. 256-264). Contexto.

Barros, L., \& Barros, M. (2014). Pista da Análise: O problema da análise em pesquisa cartográfica. In E. Passos, E, V. Kastrup, \& S. Tedesco (Orgs.), Pistas do método da cartografia: A experiência da pesquisa e o plano comum (vol. 2, pp. 1-310). Sulina.

Barros, J. P. P., Benício, L. F. S., Silva, D. B., Leonardo, C. S., \& Torres, F. J. P. (2017). Homicídios juvenis e os desafios à democracia brasileira: Implicações ético-políticas da psicologia. Psicologia: Ciência e Profissão, 37(4), 1051-1065. http://dx.doi.org/10.1590/1982-3703002892017

Barros, L. P., \& Kastrup, V. (2009). Cartografar é acompanhar processos. In E. Passos, V. Kastrup, \& L. Escóssia (Orgs.), Pistas do método da cartografia: Pesquisa-intervenção e produção de subjetividade (pp. 52-75). Sulina. 
Psicologia: Ciência e Profissão 2020 v. 40 (n.spe), e230162, 1-15.

Batista, V. M. (2003). O medo na cidade do Rio de Janeiro: dois tempos de uma história. Revan.

Benício, L. F. S., Barros, J. P. P., Rodrigues, J. S., Silva, D. B., Leonardo, C. S., \& Costa, A. F. (2018). Necropolítica e Pesquisa-intervenção sobre Homicídios de Adolescentes e Jovens em Fortaleza-Ceará [número especial]. Psicologia: Ciência e Profissão, 38(2), 192-207. https://doi.org/10.1590/1982-3703000212908

Bento, B. (2018). Necrobiopoder: Quem pode habitar o Estado-nação? Cadernos Pagu, (53), el85305. https://doi.org/ $10.1590 / 18094449201800530005$

Bicalho, P (2014). Uma carta endereçada à "proteção integral”. In G. Tavares, M. Moraes, \& A. Bernardes (Orgs.), Cartas para pensar: Politicas de pesquisa em psicologia (pp.31-40). EDUFES.

Bicalho, P. P. G., Rossotti, B. G. P. P., \& Reishoffer, J. C. (2016). A pesquisa em instituições de preservação da ordem. Revista Polis e Psique, 6(1), 85-97.

Birman, P., Leite, M., Machado, C., \& Carneiro, S. (2015). Dispositivos urbanos e trama dos viventes: Ordens e resistências. FGV.

Borges, D, \& Cano, I. (2017). Índice de homicídios na adolescência: IHA 2014. Observatório de Favelas.

Borges, J. (2018) O que é encarceramento em massa?. Letramento.

Carneiro, S. (2005). A construção do outro como não-ser como fundamento do ser [Tese de doutorado não publicada]. Universidade de São Paulo.

Coimbra, C. (2001). Operação Rio: O mito das classes perigosas. Intertexto.

Coimbra, C.M.B., \& Nascimento, M. L (2005). Ser jovem, ser pobre é ser perigoso? Imagens sobre a juventude. JOVENes: Revista de Estudios sobre Juventud, 9(22), 338-355.

Comitê Cearense Pela Prevenção De Homicídios na Adolescência (2018). Cada vida importa: Relatório do primeiro semestre de 2018 do Comitê Cearense pela Prevenção de Homicídios naAdolescência. http://cadavidaimporta.com.br/ wp-content/uploads/2018/11/CCPHA_RELATORIO_2018-1_V02.pdf

Conselho Federal de Psicologia (2017). Relações raciais: Referências técnicas para atuação de psicólogas/os. https://site.cfp.org.br/wp-content/uploads/2017/09/relacoes_raciais_baixa.pdf

Davis, A. (2018) Estarão as prisões obsoletas?. Bertrand Brasil.

Duarte, A. (2013). Policiamento comunitário e educação: Discursos de produção de uma "nova polícia” [Dissertação de mestrado, Universidade Federal do Ceará]. Repositório Institucional UFC. http://www.repositorio.ufc.br/ handle/riufc/7522

Flauzina, A. L. (2006). Corpo negro caído no chão: O sistema penal e o projeto genocida do Estado Neoliberal [Dissertação de mestrado, Universidade de Brasília]. Repositório UnB. https://repositorio.unb.br/handle/ $10482 / 5117$

Foucault, M. (1986). A Arqueologia do saber. Forense.

Foucault, M. (2008). Segurança, território, população. Martins Fontes.

Foucault, M. (2012). O que chamamos de punir?. In M. Foucault, Segurança, penalidade, prisão (pp. 280-292). Forense Universitária.

Foucault, M. (2013). De espaços outros. Estudos Avançados, 27(79), 113-122. https://doi.org/10.1590/ S0103-40142013000300008

Foucault, M. (2014). Vigiar e punir. Vozes.

Franco, M (2014). UPP: A redução da favela a três letras: Uma análise da política de segurança pública do estado do Rio de Janeiro [Dissertação de mestrado, Universidade Federal Fluminense].

Fórum Brasileiro de Segurança Pública. (2019). Anuário brasileiro de segurança pública 2019. http://www.forumseguranca.org.br/wp-content/uploads/2019/09/Anuario-2019-FINAL-v3.pdf

Gadelha, S., \& Duarte, A. (2014). O policiamento comunitário como dispositivo neoliberal de governo no campo da segurança pública. In N. Avelino, \& S. Vaccaro (Orgs.), Governamentalidade/Segurança (pp. 31-41). Intermeios.

Instituto de Pesquisa Econômica Aplicada \& Fórum Brasileiro de Segurança Pública (Orgs.). (2019). Atlas da Violência. https://www.ipea.gov.br/portal/images/stories/PDFs/relatorio_institucional/190605_atlas_da_violencia_2019.pdf 
Karam, M. (2015). Violência, militarização e guerra às drogas. In B. Kucinski, C. Dunker, D. M. Silva, D. Dara, F. Mena, G. Mingardi, I. Pereira, J. Wyllys, J. P. Peschanski, R. Moraes, L. Capriglione, L. Baltar, L. E. Soares, M. Freixo, M. L. Karam, M. R. Kehl, R. Campos, S. Graham, T. Ab'Saber, ... F. C. Branco, Bala Perdida: A violência policial no Brasil e os desafios para sua superação (pp. 33-39). Boitempo.

Kilomba, G. (2017). A máscara. Piseagrama, (11), 26-31. https://piseagrama.org/a-mascara/

Lazzarato, M (2014). Signos, máquinas, subjetividades. n-1; Edições Sesc São Paulo.

Lemos, F. C. S., Bicalho, P. P. G., Alvarez M. C., \& Brício, V. N. (2015). Governamentalidades neoliberais e dispositivo de segurança. Psicologia \& Sociedade, 27(2), 332-340.

Mbembe, A (2014). Crítica da razão negra. Antígona.

Mbembe, A (2017). Políticas da inimizade (M. Lança, Trad.). Antígona.

Mbembe, A (2019). Poder brutal, resistência visceral. n-1.

Misse, M. (2008). Sobre a construção social do crime no Brasil: Esboços de uma interpretação. In M. Misse (Org.), Acusados e acusadores: Estudos sobre ofensas, acusações e incriminações (pp.13-32). Revan.

Moreira, M. (2013). Aqui o RAIO cai no mesmo lugar: Percepções da comunidade do Lagamar em Fortaleza-CE sobre as práticas de suspeição e abordagem da Ronda de Ações Intensivas e Ostensivas (RAIO) [Dissertação de mestrado, Universidade Estadual do Ceará]. Biblioteca Digital Brasileira de Teses e Dissertações. https://bdtd.ibict.br/vufind/ Record/UECE-0_8e131cea06efa9520d721aba28b175e6

Nascimento, A (2017). O genocídio do negro brasileiro: Processos de um racismo mascarado (2a ed.). Perspectiva.

Oliveira, R. M. S., \& Nascimento, M. C. (2018). Psicologia e relações raciais: Sobre apagamentos e visibilidades. Revista da Associação Brasileira de Pesquisadores/as Negros/as (ABPN), 10(24), 216-240.

Pedro, R., Rocha, I., Castro, R. B., Gonçalves, C. S., Costa, A. J. P., \& Damasio, A. C. (2012). Redes de vigilância e segurança no Rio de Janeiro: Primeiros movimentos para uma cartografia de controvérsias. In P. Rheingantz, \& R. Pedro (Orgs.), Qualidade do lugar e cultura contemporânea: Controvérsias e ressonâncias em coletivos urbanos. (pp.17-32). Universidade Federal do Rio de Janeiro.

Pereira, A., Pontes, A., Magalhães, R., \& Maciel, T. (2018). Monitoramento da política de segurança pública do Ceará: De qual segurança pública precisamos? [Nota Técnica Especial]. Centro de Defesa da Criança e do Adolescente do Estado do Ceará. http://cedecaceara.org.br/site/wp-content/uploads/2019/06/Nota-Tecnica-Seguranca-Publica.pdf

Petruceli, J, \& Sabóia, A. (Orgs.). (2013). Características étnico-raciais da população: Classificação e identidades. IBGE. https://biblioteca.ibge.gov.br/visualizacao/livros/liv63405.pdf

Prefeitura de Fortaleza. (2014, 20 de fevereiro). Prefeitura apresenta estudo sobre Desenvolvimento Humano por bairro. https://www.fortaleza.ce.gov.br/noticias/prefeitura-apresenta-estudo-sobre-desenvolvimento-humano-por-bairro

Prefeitura de Fortaleza. (2017, 21 de dezembro). Célula da Proteção Comunitária será apresentada no Jangurussu nesta sexta-feira. https://www.fortaleza.ce.gov.br/noticias/celula-da-protecao-comunitaria-sera-apresentada-nojangurussu-nesta-sexta-feira-22

Prefeitura de Fortaleza. (2019, 20 de junho). Prefeitura de Fortaleza entrega a sexta Célula de Proteção Comunitária. https://www.fortaleza.ce.gov.br/noticias/prefeitura-de-fortaleza-entrega-a-sexta-celula-de-protecao-comunitaria

Ramos, S., \& Musumeci, L. (2005). Elemento suspeito: Abordagem policial e discriminação na cidade do Rio de Janeiro. Civilização Brasileira.

Reiner, R (2004). A Política da polícia (3a ed.). Edusp.

Schwarcz, L. M. (2019). Sobre o autoritarismo brasileiro. Companhia das Letras.

Tedesco, S. H., Sade, C., \& Caliman, L.V. (2013). A entrevista na pesquisa cartográfica: A experiência do dizer. Fractal, 25(2), 299-322. https://doi.org/10.1590/S1984-02922013000200006

Uziel, A. P., Scisleski, A. C. C., Barros, J. P. P., \& Bicalho, P. P. G. (2018). Sistema prisional e segurança pública: Inquietações e contribuições da/à psicologia. Psicologia: Ciência e Profissão, 38(spe2), 3-9. https://doi.org/ $10.1590 / 1982-3703000122018$

Wacquant, L. (2001). As prisões da miséria (André Telles, Trad.). Jorge Zahar.

Zaccone, O. (2015). Indignos de vida: A forma jurídica da política de extermínio de inimigos da idade do Rio de Janeiro. Revan. 


\section{Aldemar Ferreira da Costa}

Psicólogo e Mestrando em Psicologia pela Universidade Federal do Ceará (UFC), Integrante do Grupo de Pesquisas e Intervenções sobre Violência, Exclusão Social e Subjetivação (Vieses-UFC), Fortaleza - CE. Brasil.

E-mail: demarfcost92@gmail.com

(1) https://orcid.org/0000-0003-0281-9944

João Paulo Pereira Barros

Professor Adjunto do Departamento de Psicologia da UFC, coordenador do Programa de Pós-Graduação em Psicologia da UFC, coordenador do Vieses-UFC, doutor em Educação, mestre e graduado em Psicologia pela UFC. Especialista em Saúde Mental pela Universidade Estadual do Ceará (UECE), Fortaleza - CE. Brasil.

E-mail: joaopaulobarros07@gmail.com

(1) https://orcid.org/0000-0001-7680-576X

\section{Dagualberto Barboza da Silva}

Psicólogo e Mestrando em Psicologia pela UFC. Integrante do Vieses-UFC, Fortaleza - CE. Brasil

E-mail: dalgobarboza92@gmail.com

(1) https://orcid.org/0000-0003-3788-1780

\section{Luís Fernando de Souza Benicio}

Psicólogo pelo Centro Universitário Unifanor, mestre e doutorando em Psicologia pela UFC. Integrante do ViesesUFC. Professor substituto da UECE, Fortaleza - CE. Brasil.

E-mail: luisf.benicio@gmail.com

(1) https://orcid.org/0000-0002-0765-2568

\section{Marcus Giovani Ribeiro Moreira}

Advogado, doutorando em Sociologia pela UFC e integrante do Vieses-UFC, Fortaleza - CE. Brasil.

E-mail: marcusgigio@gmail.com

(1) https:// orcid.org/0000-0002-3622-3498

Esta pesquisa foi financiada com recursos do Conselho Nacional de Desenvolvimento Científico e Tecnológico (CNPq) e da Coordenação de Aperfeiçoamento de Pessoal de Nível Superior (CAPES).

Endereço para envio de correspondência:

Universidade Federal do Ceará. Av. da Universidade, 2762, bloco Helena Cartaxo, sala 16, $1^{\circ}$ andar, Benfica.

CEP: 60020-181. Fortaleza-CE. Brasil.

Recebido 19/10/2019

Aceito 20/11/2019

Received 10/19/2019

Approved 11/20/2019

Recibido 19/10/2019

Aceptado 20/11/2019 
Como citar: Costa, A. F, Barros, J. P. P., Silva, D. B., Benício, L. F. S., \& Moreira, M. G. M. (2020). Dispositivo de Segurança e Racionalidade Necrobiopolítica: Narrativas de Jovens Negros de Fortaleza. Psicologia: Ciência e Profissão, 40 (n.spe), 1-15. https://doi.org/10.1590/1982-3703003230162

How to cite: Costa, A. F., Barros, J. P. P., Silva, D. B., Benício, L. F. S., \& Moreira, M. G. M. (2020). Security devices and necrobiopolitics rationality: narratives of the black youth in Fortaleza. Psicologia: Ciência e Profissão, 40 (n.spe), 1-15. https:// doi.org/10.1590/1982-3703003230162

Cómo citar: Costa, A. F., Barros, J. P. P., Silva, D. B., Benício, L. F. S., \& Moreira, M. G. M. (2020). Dispositivo de seguridad y racionalidad necrobiopolítica: narrativas de jóvenes negros de Fortaleza. Psicologia: Ciência e Profissão, 40 (n.spe), 1-15. https://doi.org/10.1590/1982-3703003230162 